OPEN ACCESS

Edited by: Davide Cossu,

University of Sassari, Italy

Reviewed by:

Gunnar Houen,

Statens Serum Institut (SSI), Denmark Andrea Manca,

University of Sassari, Italy

${ }^{*}$ Correspondence: Jessica Frau jessicafrauneuro@gmail.com

Specialty section: This article was submitted to Multiple Sclerosis and Neuroimmunology, a section of the journal

Frontiers in Immunology

Received: 21 June 2021 Accepted: 20 September 2021 Published: 06 October 2021

Citation:

Frau J, Coghe G, Lorefice L, Fenu G and Cocco E (2021) Infections and Multiple Sclerosis: From the World to Sardinia, From Sardinia to the World.

Front. Immunol. 12:728677. doi: 10.3389/fimmu.2021.728677

\section{Infections and Multiple Sclerosis: From the World to Sardinia, From Sardinia to the World}

\author{
Jessica Frau*, Giancarlo Coghe, Lorena Lorefice, Giuseppe Fenu and Eleonora Cocco \\ Multiple Sclerosis Centre, Azienda Tutela Salute (ATS) Sardegna, University of Cagliari, Cagliari, Italy
}

Multiple Sclerosis (MS) is an inflammatory disease of the central nervous system. Sardinia, an Italian island, is one of the areas with the highest global prevalence of MS. Genetic factors have been widely explored to explain this greater prevalence among some populations; the genetic makeup of the Sardinians appears to make them more likely to develop autoimmune diseases. A strong association between MS and some infections have been reported globally. The most robust evidence indicating the role of infections is MS development concerns the Epstein-Barr virus (EBV). Anti-EBV antibodies in patients once infected by EBV are associated with the development of MS years later. These features have also been noted in Sardinian patients with MS. Many groups have found an increased expression of the Human endogenous retroviruses (HERV) family in patients with MS. A role in pathogenesis, prognosis, and prediction of treatment response has been proposed for HERV. A European multi-centre study has shown that their presence was variable among populations, ranging from 59\% to 100\% of patients, with higher HERV expression noted in Sardinian patients with MS. The mycobacterium avium subspecies paratuberculosis (MAP) DNA and antibodies against MAP2694 protein were found to be associated with MS in Sardinian patients. More recently, this association has also been reported in Japanese patients with MS. In this study, we analysed the role of infectious factors in Sardinian patients with MS and compared it with the findings reported in other populations.

Keywords: multiple sclerosis, Epstein - Barr virus, human endogeneous retrovirus-W, mycobacterium avium subspecies paratuberculosis, infections, genetic, Sardinia (Italy)

\section{INTRODUCTION}

Multiple Sclerosis (MS) is an autoimmune disease of the central nervous system with an increasing incidence and prevalence in geographical regions with higher latitude, in both the hemispheres (1). Recent data indicates the incidence of MS in areas of lower latitude, as well as its prevalence, has increased in Europe and North America, with a high MS incidence in some southern areas (2). Nevertheless, it is known as an exception to this gradient Sardinia, an Italian island where the presence of MS is among the highest worldwide. The prevalence of the disease in Sardinia is 361/ 100,000 inhabitants (3). The Sardinian population has a peculiar genetic background that could partly explain this primacy $(4,5)$. To note, the main predisposing risk factor for MS in North 
Europeans is the HLA-DRB1 ${ }^{\star} 15$ ( $\left.{ }^{*} \mathrm{DRB} 1-15: 01-\mathrm{DQB} 1{ }^{\star} 06: 02\right)$, while in Sardinian population the predisposing ${ }^{\star} 15: 01$ is virtually absent and MS is associated in particular to ${ }^{\star} 13: 03-{ }^{\star} 03: 01$, ${ }^{\star} 04: 05-{ }^{\star} 03: 01$, and ${ }^{\star} 03: 01-{ }^{\star} 02: 01(4,5)$. On the other hand, a protective role in Sardinians has been found for $\mathrm{DRB} 1^{\star} 15: 02$, $\mathrm{DRB}^{\star}{ }^{\star} 16: 01, \mathrm{DQB} 1^{\star} 06: 01$, and $\mathrm{DQB} 1{ }^{\star} 05: 02$ (4). Thus, the propensity to MS in Sardinians may be due to a complex presence of various HLA-DRB1-DQB1, from which the modality of antigen presentation depends (5).

Moreover, it is known that genetic factors alone are not sufficient for the presentation of the disease, and many environmental factors, particularly that affect the individuals in the first decades of life, are involved in the pathogenesis of MS (2, 6). Typically, the risk factors of MS have been classified into two groups: non-infectious and infectious. In the first group, lack of sunlight exposure, low levels of vitamin D, cigarette smoking, and a diet high in animal/saturated fats are reportedly associated with the development of MS $(2,6)$.

The association between infectious factors and the development of MS has been widely reported for a long time. Even in the seventies, elevated titres of rubeola, measles, and vaccinia viruses were noted in the cerebrospinal fluid (CSF) of patients with MS, and a role of persistent or slow infections was hypothesised (7). Particular attention was given to herpes viruses, while in the eighties, an Italian cooperative study found higher titres of antibodies against herpes simplex 2 and Epstein Barr virus (EBV) in patients with MS than in healthy controls and those with other neurological diseases (8). A possible association with Herpes human virus 6 (HHV-6) has been hypothesised from the nineties; however, controversial results have been described (9). To note, a recent metanalysis confirmed an association between HHV-6 and MS (10). Antibodies against measles, rubella, and herpes zoster virus (MRZ reaction) are present in $80 \%-100 \%$ of patients with MS (11), and their presence in patients with clinically isolated syndrome appears to predict the conversion to MS (12). Data about varicella-zoster, herpes simplex 1 and 2 , and cytomegalovirus are conflicting and inconclusive (13).

The viruses involved in MS could manipulate the gene expression of the host, leading to immune deregulation and tissue damage; moreover, they can enter the brain and establish latent chronic infection (14).

Different mechanisms have been hypothesised for the involvement of viruses in MS pathogenesis and they are not mutually exclusive. Viruses can act as triggers or co-factors in the development of the disease. They could cause direct toxicity in the affected neurons (9); the $\mathrm{T}$ cell receptor (TCR) in the T lymphocyte surface could be specific for both virus and myelin antigens (15); after causing tissue damage, viruses can facilitate an over-reactive inflammation due to the exposition of hidden antigens, with the production of autoreactive immunity cells (bystander activation) (16); secondary to myelin disruption, its fragments are released in the inflammatory environment and new epitopes are exposed to inflammatory cells (epitope spreading) (17). The control of autoreactive cells is dependent on T regulatory cells; however, they appear defective in MS (18).
The more accredited mechanism to explain the involvement of viruses in autoimmune diseases such as MS is molecular mimicry. T cells specific for non-self epitopes cross-react with self-epitopes that are similar peptides, causing tissue damage (19, $20)$. In the case of MS, molecular mimicry between myelin basic protein (MBP) and EB nuclear antigen 1 (EBNA-1) is well established, and peptides deriving from both MBP and EBNA1 could activate CD8+ T cells isolated from patients with MS (20). Moreover, T helper 1 (Th1) and Th1/17 are the main subsets in MS responding to peptides derived from myelin and viruses as EBV. Th1/17 isolated from CSF of patients with MS react both with self-antigen-presenting cells and peptides from viruses and bacteria (21).

To note, many disease-modifying therapies target cells in which viruses such as EBV and Human endogenous retroviruses (HERV) have been found, and it has been postulated that part of their effects could be explained by reducing HBV and HERV-W autoreactive cells (13).

\section{EBV}

EBV is related to several diseases that develop years after the primary infection. It has been hypothesised that a decreased capacity to control EBV by the immune system could promote the onset of late EBV-related diseases, such as cancer, MS, and other autoimmune disorders (22). A defective T cell control of EBV in patients with MS has been reported (23).

The prevalence of EBV seropositivity in patients with MS is approximately $100 \%$ and a history of mononucleosis is a risk factor in the development of the disease $(24,25)$. Various studies estimate that previous EBV infection with mononucleosis increases the risk of MS to the same degree as that of carrying human-leukocyte antigen (HLA) DRB1 $15^{*} 01$, which is the strongest genetic factor associated with the disease (26). The detection of anti-EBV antibodies is associated with the onset of MS after 5-20 years after EBV infection (27).

Signs of EBV infections in the brain and CSF of patients with MS have been reported by some researchers, whereas this was not reported in other studies (28). Nevertheless, the presence of EBV in the brain could be not a peculiar characteristic of MS. Moreover, many viruses persisting in a latent stage are neurotrophic and could be found inside the brain (22). Recently, antibodies against specific epitopes in EBNA-1 crossreacting with MBP have been recognised in the sera of patients with MS and not of healthy controls (29).

If the detection of EBV antibodies in patients with MS is increased, similar results are not found searching for DNA in biological fluids like blood, CSF, and saliva. This datum suggests that the role of EBV is not related to reactivation, which could be occasionally possible, but to the latent infection (22).

Various mechanisms have been proposed to explain EBV involvement in MS pathogenesis, such as molecular mimicry with MBP, an autoimmune response against alpha-betacrystallin, and both complement and antibody-dependent cellular cytotoxicity (13).

EBNA-2 inside the host cells binds within genetic loci associated with MS (30). By EBNA-2 binding site, EBV could 
convert resting B cells into immortal B cells, which maintain autoreactive cells within the brain and blood of patients with MS (31).

In the MS Sardinian population, EBV DNA was detected more in patients than in controls (32), and a higher prevalence of anti EBNA1 antibodies has been found in those without diseasemodifying treatments (DMTs) when compared to healthy controls (33). Antibodies titres decreased after 6 months of interferon beta, both in the Sardinian cohort and in other populations $(33,34)$.

Regarding DMTs, it has been hypothesised that CD20 monoclonal antibodies could exert their efficacy in eliminating EBV-infected memory B cells (22). In addition, the effect of natalizumab could be partially related to reduced mobility of EBV into CNS, both inhibiting the entry of EBV mediated by integrin, and blocking the lymphocyte trafficking, including that of EBV-infected B cells and EBV-directed T cells (35). Additionally, teriflunomide could influence the immune response to EBV and reduce their lytic replication (36).

\section{HERV}

They are a group of retroviruses incorporated in the human genome millions of years ago, representing approximately $8 \%$ of the entire genome, and have regulatory functions for human gene expression (13). In contrast, when their expression is inappropriate, they should cause inflammation, aberrant immune expression, and deregulated gene expression (37-39).

The association of MS with the three types of HERV (HERV$\mathrm{H}$, HERV-K, and HERV-W), in particular the latter, has been demonstrated by various studies (40). Nevertheless, the presence of HERV-W is not specific for MS and is also found in patients with other non-inflammatory neurological diseases (41), and in close relatives of patients with MS, possibly being a predisposing factor for the disease (42). In contrast, in a study analysing northSardinian population, the association was found with MS and myelin oligodendrocyte glycoprotein (MOG)-IgG associated disorders, but not with optic neuromyelitis (NMO) (43). There is a probably molecular mimicry between HERV-W antigen and oligodendrocytes, which are primarily affected in MS, but not with astrocytes, which are primarily affected in NMO.

The proportion of patients with MS positive for HERV-W MS-associated retrovirus (MSRV) varies from 50\% to $100 \%$ among the populations (44-46). This variability could be explained both with the heterogeneity of populations in terms of HERV expression, and the different detection methods used (13). In a European multicentre study, HERV-W was detected in approximately $100 \%$ of Sardinian patients with MS, while its presence was lower in other populations. Probably, a genetic selection in an isolated island has promoted the genome of Sardinians to contain high copies of HERV-W, with better circulation in a closed population (46). The presence of HERV$\mathrm{W}$ viraemia has also been detected in $9 \%$ of healthy Caucasian blood donors (47); its positivity in the blood of patients with initially isolated optic neuritis is higher than in healthy controls and predicts the conversion to MS in the next 20 months (48).

In general, its expression could be modified not only by mutations, but also by retroviral restriction factors, external events such as viral infections, and epigenetic mechanisms and could directly activate the retrovirus or deregulate the mechanism preventing its expression (40). To note, an altered epigenetic regulation has been described in patients with MS (49), and the same alteration could be involved in the expression of MSRV.

HERV-W envelope (env) protein has been detected in the surface of macrophages and microglia in the brain of patients with MS near demyelinating lesions, and this protein share homologous sequences with MOG, being able to activate $\mathrm{T}$ and B cells (50).

Studies performed in patients with MS from Sardinia found that the presence of HERV-W products in the blood has been associated with poor prognosis $(48,51)$, while in the CSF it is more detected during relapses than during the remission phase (41), and its presence in CSF is associated with disability accumulation and higher relapse rate (51).

The MSRV load is higher in women with active MS, and it is correlated to a higher Expanded Disability Status Scale (EDSS)/ Multiple Sclerosis Severity Score (MSSS) (52). The expression of MSRV is higher in MS patients with secondary progressive courses (40).

Regarding the detection of antibodies against HERV-W and HERV-H, they are higher during relapses than in the remission phase, and their levels correlate with higher expression of HERV$\mathrm{W}$ env and HERV-H env in B cells and monocytes only during relapses (53).

A study performed in a Sardinian population shown that treatment with natalizumab reduced the expression of the MSRV/syncytin-1/HERV-W (54), as well viremia fell below detection limits during efficacious therapy with interferon beta and other treatments as fingolimod, azathioprine, and glatiramer acetate $(55,56)$.

The main implicated proteins are MSRV env and syncytin-1. They are expressed by B cells, monocytes, natural killer but not $\mathrm{T}$ cells (57), and have pro-inflammatory and superantigenic properties, and could cause inflammation, neurodegeneration, stress response, and altered immune response (56).

It is known that HERV-W cross-react with MOG, and it can bind CD14 and Toll-like receptor 4, promoting the release of pro-inflammatory cytokines (13).

Furthermore, its expression in myeloid cells into CNS induces a degenerative phenotype with axonal damage, and could also inhibit remyelination by reduced formation of oligodendrocytes precursor cells and promotion of pro-inflammatory cytokines (58). This last effect could be blocked by an anti-HERV monoclonal antibody (59).

The retrovirus can be activated by infections, and EBV appears to be its main activator. In particular, it could be triggered by the latent EBV phase, acting as an effector for MS $(57,60)$. Their interaction in the blood could induct the HERV$\mathrm{W}$ env superantigen properties, while in the brain toxic mechanisms against oligodendrocytes could be involved, enhancing inflammation, demyelination, and axonal damage (57). High titres of anti-EBNA antibodies can be observed 15-20 years before the MS onset (61), with high expression of HERV-W simultaneously (60). 


\section{Mycobacterium avium Subspecies Paratuberculosis (MAP)}

Different mycobacteria have been identified in association with MS, and the TCR levels, important in recognizing mycobacteria, are increased in patients with MS (62).

It was primarily associated with MS in a Sardinian population (63). In particular, MAP DNA has been repeatedly found in a higher percentage of patients with MS than in healthy donors $(32,63,64)$. Moreover, MAP antigens sharing epitopes with MSrelated proteins can promote a high immune response both in blood and CSF of patients with MS, probably acting by molecular mimicry (63-65). In particular, a humoral response against the MAP2694 antigen, which is homologous of TCR gamma chain C region and the complement component 1 , was found in approximately $34 \%$ of patients and only $10 \%$ of healthy controls (64). Moreover, heat shock proteins (HSP) of mycobacteria share homologous sequences with human proteins, thus promoting an autoimmune response by molecular mimicry (66). It is known that the lymphocyte proliferative response against some HSPs derived from mycobacteria is higher in patients with MS than in those with other neurological diseases or healthy controls $(67,68)$. Sardinian patients with MS have increased levels of antibodies against the MAP recombinant protein FprB and the MAP HSP70 $(32,69)$. In contrast, no antibodies have been found against a MAP epitope homologous to MOG (70).

Several MAP proteins and antigenic epitopes can induce a stronger immune response in patients with MS than in other patients (70).

Moreover, antibodies against several homologous epitopes of MAP, EBV, and humans have been found in CSF and blood samples of patients with MS (65). A common target of MAP and EBV in triggering autoimmune response could be MBP. In particular, both the pathogens should induce antibodies that cross-recognise some MBP peptides, which have conformational similarities with MAP and EBV antigens $(65,71,72)$.

In a small study performed in Sardinian patients, crossrecognition of MAP and EBV epitopes $\left(B O L F 1_{305-320}\right.$ and MAP_402718-32) and the self-epitope IRF5 $424-434$ appears to regulate the immune dysregulation in MS (73). Later, another study confirmed that in patients with MS, autoantibodies recognising MBP and IRF5 cross-react with homologous peptides from MAP and EBV, primarily owing to molecular mimicry.

It is likely that similar to other autoimmune diseases, MAP infection could enhance the risk of MS; however, other factors such as genetic susceptibility are fundamental for the development of MS. In individuals with higher susceptibility to mycobacterial infections, gene polymorphisms related to MS, such as the HLA complex, vitamin D receptor, TCL, and others have been detected (74).

In the Sardinian cohort of patients with MS, a lower proportion of patients carrying oligoclonal bands were MAP positive, probably because the action of MAP was primarily expressed in the periphery (64). Moreover, MAP DNA was detected more commonly in patients with recent steroid pulse therapy, while anti MAP2694 antibodies were detected in those taking interferon beta $(64,75)$.
More recently, an association between MAP and MS was found in Japan. A higher response of antibodies against surface antigens has been detected, with antibodies against MAP2694 present in $30 \%$ of patients, a significantly higher rate compared to healthy controls and those with other neurological diseases $(76,77)$. It has been highlighted that this MAP antigen can bind more to the HLA 1501 and 0301, which predisposes to MS than the protective haplotypes 1601 and $15^{\star} 02$. Thus, T cells are easily activated for inducing autoimmunity (78). In Sardinian and Japanese patients with MS the disease is associated with $\mathrm{DPB} 1^{\star} 0301$, which is a genetic peculiarity (77).

The association between genetic factors and MAP has been analysed in Sardinian patients, and no association has been found with MAP positivity and predisposing haplotypes. Nevertheless, there was a lower detection of anti MAP antibodies in patients carrying at least one protective haplotype versus those without it (79). Moreover, an association between MAP and SLC11A1 polymorphism has been found consistently in the Sardinian MS cohort (80). This gene is important in the defence against intracellular pathogens; however, its role as an MS-associated gene is controversial (80).

When Japanese patients with MS and NMO were compared, anti MAP2694 antibodies were higher in blood and CSF of the first group than that of the latter (81). In NMO Sardinians patients, a humoral response against MAP antigens has been detected; however, there was no relationship between this response and the presence of anti AQP4 antibodies. Moreover, the same study demonstrated that MAP is unable to infect and persist within astrocytes (82).

\section{CONCLUSIONS}

Many infectious factors have been studied worldwide for their presumed association with MS, both in its pathogenesis and the course of the disease.

EBV is the primarily implicated, and MS could be retained, as some types of cancer, a rare and late complication of EBV infection.

HERV-W has been found to be associated with MS in many populations; however, the incidence varies with the geographical area. A strong dependence has been found from EBV infection in triggering MS.

MAP has been studied only in Sardinia and Japan and both the populations are associated with MS. As postulated by other authors the relationship between MAP and MS could be population-specific, and dependent on both genetic and non-genetic factors (77).

Sometimes, a genetic variant protective against a specific disease increases the risk of another disease. This is the case of a variant of tumour necrosis factor superfamily $13 \mathrm{~B}$, gene encoding for the B-cell activating factor (BAFF). It was selected in the past in Sardinia as it could provide resistance from malaria, which was endemic on the island. In contrast, it enhances levels of BAFF, B cells, and immunoglobulins, favouring autoimmunity similar to MS (83).

Recently, the PRF1:p.A91V mutation, which causes an increase of lymphocytes (particularly cytotoxic memory T cells) and perforin 
deficiency, has been associated with MS. This same mutation, when reinforced by environmental factors such as herpes infections, could favour an exaggerated activation of the immune system and trigger familial haemophagocytic lymphohistiocytosis (84).

In conclusion, genetic and other environmental factors are critical for the onset of MS, which appears to be dependent on their complex interaction.

\section{REFERENCES}

1. Kurtzke JF. A Reassessment of the Distribution of Multiple Sclerosis. Part One. Acta Neurol Scand (1975) 51(2):110-36. doi: 10.1111/j.16000404.1975.tb01364.x

2. Ascherio A, Munger KL. Environmental Risk Factors for Multiple Sclerosis. Part I: The Role of Infection. Ann Neurol (2007) 61(4):288-99. doi: $10.1002 /$ ana.21117

3. Barometro AISM 2019. Available at: https:/www.aism.it/sites/default/files/ Barometro_della_SM_2019estratto.pdf.

4. Cocco E, Sardu C, Pieroni E, Valentini M, Murru R, Costa G, et al. HLADRB1-DQB1 Haplotypes Confer Susceptibility and Resistance to Multiple Sclerosis in Sardinia. PloS One (2012) 7(4):e33972. doi: 10.1371/ journal.pone.0033972

5. Cocco E, Murru R, Costa G, Kumar A, Pieroni E, Melis C, et al. Interaction Between HLA-DRB1-DQB1 Haplotypes in Sardinian Multiple Sclerosis Population. PloS One (2013) 8(4):e59790. doi: 10.1371/journal.pone.0059790

6. Ascherio A, Munger KL. Environmental Risk Factors for Multiple Sclerosis. Part II: Noninfectious Factors. Ann Neurol (2007) 61(6):504-13. doi: 10.1002/ ana.21141

7. Adams JM. Persistent or Slow Viral Infections and Related Diseases. West J Med (1975) 122(5):380-93.

8. Ferrante P, Castellani P, Barbi M, Bergamini F. The Italian Cooperative Multiple Sclerosis Case-Control Study: Preliminary Results on Viral Antibodies. Ital J Neurol Sci (1987) Suppl 6:45-50.

9. Donati D. Viral Infections and Multiple Sclerosis. Drug Discov Today Dis Models (2020) 32:27-33. doi: 10.1016/j.ddmod.2020.02.003

10. Pormohammad A, Azimi T, Falah F, Faghihloo E. Relationship of Human Herpes Virus 6 and Multiple Sclerosis: A Systematic Review and MetaAnalysis. J Cell Physiol (2018) 233(4):2850-62. doi: 10.1002/jcp.26000

11. Jarius S, Eichhorn P, Franciotta D, Petereit HF, Akman-Demir G, Wick M, et al. The MRZ Reaction as a Highly Specific Marker of Multiple Sclerosis: Reevaluation and Structured Review of the Literature. J Neurol (2017) 264:453-66. doi: 10.1007/s00415-016-8360-4

12. Brettschneider J, Tumani H, Kiechle U, Muche R, Richards G, Lehmensiek V, et al. IgG Antibodies Against Measles, Rubella, and Varicella Zoster Virus Predict Conversion to Multiple Sclerosis in Clinically Isolated Syndrome. PloS One (2009) 4(11):e7638. doi: 10.1371/journal.pone.0007638

13. Tarlinton RE, Martynova E, Rizvanov AA, Khaiboullina S, Verma S. Role of Viruses in the Pathogenesis of Multiple Sclerosis. Viruses (2020) 12(6):643. doi: 10.3390/v12060643

14. Niedobitek G, Meru N, Delecluse HJ. Epstein-Barr Virus Infection and Human Malignancies. Int J Exp Pathol (2001) 82(3):149-70. doi: 10.1111/ j.1365-2613.2001.iep190.x

15. Cusick MF, Libbey JE, Fujinami RS. Multiple Sclerosis: Autoimmunity and Viruses. Curr Opin Rheumatol (2013) 25(4):496-501. doi: 10.1097/ BOR.0b013e328362004d

16. Duke RC. Self Recognition by T Cells. I. Bystander Killing of Target Cells Bearing Syngeneic MHC Antigens. J Exp Med (1989) 170(1):59-71. doi: 10.1084/jem.170.1.59

17. Lehmann PV, Forsthuber T, Miller A, Sercarz EE. Spreading of T-Cell Autoimmunity to Cryptic Determinants of an Autoantigen. Nature (1992) 358(6382):155-7. doi: 10.1038/358155a0

18. Kleinewietfeld M, Hafler DA. The Plasticity of Human Treg and Th17 Cells and Its Role in Autoimmunity. Semin Immunol (2013) 25(4):305-12. doi: 10.1016/j.smim.2013.10.009

\section{AUTHOR CONTRIBUTIONS}

JF collected the literature, designed the review, and wrote the paper. GC designed, wrote and revised critically the paper. LL and GF designed and revised critically the paper. EC concepted, designed and revised critically the review. All authors contributed to the article and approved the submitted version.

19. Fujinami RS, Oldstone MB. Amino Acid Homology Between the Encephalitogenic Site of Myelin Basic Protein and Virus: Mechanism for Autoimmunity. Science (1985) 230(4729):1043-5. doi: 10.1126/science.2414848

20. Wucherpfennig KW, Strominger JL. Molecular Mimicry in T Cell-Mediated Autoimmunity: Viral Peptides Activate Human T Cell Clones Specific for Myelin Basic Protein. Cell (1995) 80(5):695-705. doi: 10.1016/0092-8674(95) 90348-8

21. Paroni M, Maltese V, De Simone M, Ranzani V, Larghi P, Fenoglio C, et al. Recognition of Viral and Self-Antigens by TH1 and TH1/TH17 Central Memory Cells in Patients With Multiple Sclerosis Reveals Distinct Roles in Immune Surveillance and Relapses. J Allergy Clin Immunol (2017) 140 (3):797-808. doi: 10.1016/j.jaci.2016.11.045

22. Houen G, Trier NH, Frederiksen JL. Epstein-Barr Virus and Multiple Sclerosis. Front Immunol (2020) 11:587078. doi: 10.3389/fimmu.2020.587078

23. Pender MP, Csurhes PA, Burrows JM, Burrows SR. Erratum: Defective T-Cell Control of Epstein-Barr Virus Infection in Multiple Sclerosis. Clin Transl Immunol (2017) 6(6):e147. doi: 10.1038/cti.2017.25

24. Pakpoor J, Ramagopalan SV. Epstein-Barr Virus Is a Necessary Causative Agent in the Pathogenesis of Multiple Sclerosis: Yes. Mult Scler (2013) 19 (13):1690-1. doi: 10.1177/1352458513506505

25. Handel AE, Williamson AJ, Disanto G, Handunnetthi L, Giovannoni G, Ramagopalan SV. An Updated Meta-Analysis of Risk of Multiple Sclerosis Following Infectious Mononucleosis. PloS One (2010) 5(9):e12496. doi: 10.1371/journal.pone.0012496

26. Geginat J, Paroni M, Pagani M, Galimberti D, De Francesco R, Scarpini E, et al. The Enigmatic Role of Viruses in Multiple Sclerosis: Molecular Mimicry or Disturbed Immune Surveillance? Trends Immunol (2017) 38(7):498-512. doi: 10.1016/j.it.2017.04.006

27. Munger KL, Levin LI, O'Reilly EJ, Falk KI, Ascherio A. Anti-Epstein-Barr Virus Antibodies as Serological Markers of Multiple Sclerosis: A Prospective Study Among United States Military Personnel. Mult Scler (2011) 17 (10):1185-93. doi: 10.1177/1352458511408991

28. Lassmann H, Niedobitek G, Aloisi F, Middeldorp JMNeuroproMiSe EBV Working Group. Epstein-Barr Virus in the Multiple Sclerosis Brain: A Controversial Issue-Report on a Focused Workshop Held in the Centre for Brain Research of the Medical University of Vienna, Austria. Brain 134 (Pt 9):2772-86. doi: 10.1093/brain/awr197

29. Jog NR, McClain MT, Heinlen LD, Gross T, Towner R, Guthridge JM, et al. Epstein Barr Virus Nuclear Antigen 1 (EBNA-1) Peptides Recognized by Adult Multiple Sclerosis Patient Sera Induce Neurologic Symptoms in a Murine Model. J Autoimmun (2020) 106:102332. doi: 10.1016/j.jaut.2019.102332

30. Ricigliano VA, Handel AE, Sandve GK, Annibali V, Ristori G, Mechelli R, et al. EBNA2 Binds to Genomic Intervals Associated With Multiple Sclerosis and Overlaps With Vitamin D Receptor Occupancy. PloS One (2015) 10(4): e0119605. doi: 10.1371/journal.pone.0119605

31. Zhao B, Zou J, Wang H, Johannsen E, Peng CW, Quackenbush J, et al. Epstein-Barr Virus Exploits Intrinsic B-Lymphocyte Transcription Programs to Achieve Immortal Cell Growth. Proc Natl Acad Sci USA (2011) 108 (36):14902-7. doi: 10.1073/pnas.1108892108

32. Cossu D, Masala S, Cocco E, Paccagnini D, Frau J, Marrosu MG, et al. Are Mycobacterium Avium Subsp. Paratuberculosis and Epstein-Barr Virus Triggers of Multiple Sclerosis in Sardinia? Mult Scler (2012) 18(8):1181-4. doi: $10.1177 / 1352458511433430$

33. Mameli G, Cossu D, Cocco E, Masala S, Frau J, Marrosu MG. Sechi LA EBNA1 IgG Titers in Sardinian Multiple Sclerosis Patients and Controls. J Neuroimmunol (2013) 264(1-2):120-2. doi: 10.1016/j.jneuroim.2013.07.017 
34. Comabella M, Kakalacheva K, Río J, Münz C, Montalban X, Lünemann JD. EBV-Specific Immune Responses in Patients With Multiple Sclerosis Responding to Ifn $\beta$ Therapy. Mult Scler (2012) 18(5):605-9. doi: 10.1177/ 1352458511426816

35. Shannon-Lowe C, Rowe M. Epstein Barr Virus Entry; Kissing and Conjugation. Curr Opin Virol (2014) 4:78-84. doi: 10.1016/j.coviro. 2013.12.001

36. Zivadinov R, Ramanathan M, Hagemeier J, Bergsland N, Ramasamy DP, Durfee J, et al. Teriflunomide's Effect on Humoral Response to Epstein-Barr Virus and Development of Cortical Gray Matter Pathology in Multiple Sclerosis. Mult Scler Relat Disord (2019) 36:101388. doi: 10.1016/j.msard. 2019.101388

37. Ariza ME, Williams MV. A Human Endogenous Retrovirus K Dutpase Triggers a TH1, TH17 Cytokine Response: Does it Have a Role in Psoriasis? J Investig Dermatol (2011) 131:2419-27. doi: 10.1038/jid.2011.217

38. Saito T, Miyagawa K, Chen SY, Tamosiuniene R, Wang L, Sharpe O, et al. Upregulation of Human Endogenous Retrovirus-K Is Linked to Immunity and Inflammation in Pulmonary Arterial Hypertension. Circulation (2017) 136:1920-35. doi: 10.1161/CIRCULATIONAHA.117.027589

39. Grandi N, Tramontano E. Type W Human Endogenous Retrovirus (HERVW) Integrations and Their Mobilization by L1 Machinery: Contribution to the Human Transcriptome and Impact on the Host Physiopathology. Viruses (2017) 9:162. doi: 10.3390/v9070162

40. Morandi E, Tarlinton RE, Tanasescu R, Gran B. Human Endogenous Retroviruses and Multiple Sclerosis: Causation, Association, or After-Effect? Mult Scler (2017) 23(8):1050-5. doi: 10.1177/1352458517704711

41. Dolei A, Serra C, Mameli G, Pugliatti M, Sechi G, Cirotto MC, et al. Multiple Sclerosis-Associated Retrovirus (MSRV) in Sardinian MS Patients. Neurology (2002) 58(3):471-3. doi: 10.1212/WNL.58.3.471

42. de Villiers JN, Treurnicht FK, Warnich L, Carr J, van Rensburg SJ, Kotze MJ. Analysis of Viral and Genetic Factors in South African Patients With Multiple Sclerosis. Metab Brain Dis (2006) 21(2-3):163-9. doi: 10.1007/s11011-0069016-3

43. Arru G, Sechi E, Mariotto S, Zarbo IR, Ferrari S, Gajofatto A, et al. Antibody Response Against HERV-W in Patients With MOG-IgG Associated Disorders, Multiple Sclerosis and NMOSD. J Neuroimmunol (2020) 338:577110. doi: 10.1016/j.jneuroim.2019.577110

44. Garson JA, Tuke PW, Giraud P, Paranhos-Baccala G, Perron H. Detection of Virion-Associated MSRV-RNA in Serum of Patients With Multiple Sclerosis. Lancet (1998) 351(9095):33. doi: 10.1016/S0140-6736(98)24001-3

45. Serra C, Sotgiu S, Mameli G, Pugliatti M, Rosati G, Dolei A. Multiple Sclerosis and Multiple Sclerosis-Associated Retrovirus in Sardinia. Neurol Sci (2001) 22 (2):171-3. doi: 10.1007/s100720170019

46. Arru G, Mameli G, Astone V, Serra C, Huang YM, Link H, et al. Multiple Sclerosis and HERV-W/MSRV: A Multicentric Study. Int J BioMed Sci (2007) 3(4):292-7.

47. Dolei A, Perron H. The Multiple Sclerosis-Associated Retrovirus and Its HERV-W Endogenous Family: A Biological Interface Between Virology, Genetics, and Immunology in Human Physiology and Disease. J Neurovirol (2009) 15(1):4-13. doi: 10.1080/13550280802448451

48. Sotgiu S, Arru G, Söderström M, Mameli G, Serra C, Dolei A. Multiple Sclerosis-Associated Retrovirus and Optic Neuritis. Mult Scler (2006) 12 (3):357-9. doi: 10.1191/135248506ms1303sr

49. Küçükali Cİ, Kürtüncü M, Çoban A, Çebi M, Tüzün E. Epigenetics of Multiple Sclerosis: An Updated Review. Neuromol Med (2015) 17(2):83-96. doi: 10.1007/s12017-014-8298-6

50. Morris G, Maes M, Murdjeva M, Puri BK. Do Human Endogenous Retroviruses Contribute to Multiple Sclerosis, and If So, How? Mol Neurobiol (2019) 56(4):2590-605. doi: 10.1007/s12035-018-1255-x

51. Sotgiu S, Serra C, Mameli G, Pugliatti M, Rosati G, Arru G, et al. Multiple Sclerosis-Associated Retrovirus and MS Prognosis: An Observational Study. Neurology (2002) 59(7):1071-3. doi: 10.1212/WNL.59.7.1071

52. García-Montojo M, de la Hera B, Varadé J, de la Encarnación A, Camacho I, Domínguez-Mozo M, et al. HERV-W Polymorphism in Chromosome X Is Associated With Multiple Sclerosis Risk and With Differential Expression of MSRV. Retrovirology (2014) 11:2. doi: 10.1186/1742-4690-11-2

53. Brudek T, Christensen T, Aagaard L, Petersen T, Hansen HJ, Møller-Larsen A. B Cells and Monocytes From Patients With Active Multiple Sclerosis Exhibit
Increased Surface Expression of Both HERV-H Env and HERV-W Env, Accompanied by Increased Seroreactivity. Retrovirology (2009) 6:104. doi: 10.1186/1742-4690-6-104

54. Arru G, Leoni S, Pugliatti M, Mei A, Serra C, Delogu LG, et al. Natalizumab Inhibits the Expression of Human Endogenous Retroviruses of the W Family in Multiple Sclerosis Patients: A Longitudinal Cohort Study. Mult Scler (2014) 20(2):174-82. doi: 10.1177/1352458513494957

55. Mameli G, Serra C, Astone V, Castellazzi M, Poddighe L, Fainardi E, et al. Inhibition of Multiple-Sclerosis-Associated Retrovirus as Biomarker of Interferon Therapy. J Neurovirol (2008) 14(1):73-7. doi: 10.1080/ 13550280701801107

56. Dolei A. The Aliens Inside Us: HERV-W Endogenous Retroviruses and Multiple Sclerosis. Mult Scler (2018) 24(1):42-7. doi: 10.1177/ 1352458517737370

57. Mameli G, Poddighe L, Mei A, Uleri E, Sotgiu S, Serra C, et al. Expression and Activation by Epstein Barr Virus of Human Endogenous Retroviruses-W in Blood Cells and Astrocytes: Inference for Multiple Sclerosis. PloS One (2012) 7 (9):e44991. doi: 10.1371/journal.pone.0044991

58. Kremer D, Schichel T, Förster M, Tzekova N, Bernard C, van der Valk P, et al. Human Endogenous Retrovirus Type W Envelope Protein Inhibits Oligodendroglial Precursor Cell Differentiation. Ann Neurol (2013) 74 (5):721-32. doi: 10.1002/ana.23970

59. Kremer D, Förster M, Schichel T, Göttle P, Hartung HP, Perron H, et al. The Neutralizing Antibody GNbAC1 Abrogates HERV-W Envelope ProteinMediated Oligodendroglial Maturation Blockade. Mult Scler (2015) 21 (9):1200-3. doi: 10.1177/1352458514560926

60. Mameli G, Madeddu G, Mei A, Uleri E, Poddighe L, Delogu LG, et al. Activation of MSRV-Type Endogenous Retroviruses During Infectious Mononucleosis and Epstein-Barr Virus Latency: The Missing Link With Multiple Sclerosis? PloS One (2013) 8(11):e78474. doi: 10.1371/journal.pone.0078474

61. Coppotelli G, Mughal N, Callegari S, Sompallae R, Caja L, Luijsterburg MS, et al. The Epstein-Barr Virus Nuclear Antigen-1 Reprograms Transcription by Mimicry of High Mobility Group A Proteins. Nucleic Acids Res (2013) 41:2950-62. doi: 10.1093/nar/gkt032

62. Cossu D, Yokoyama K, Hattori N. Conflicting Role of Mycobacterium Species in Multiple Sclerosis. Front Neurol (2017) 8:216. doi: 10.3389/ fneur.2017.00216

63. Cossu D, Cocco E, Paccagnini D, Masala S, Ahmed N, Frau J, et al. Association of Mycobacterium Avium Subsp. Paratuberculosis With Multiple Sclerosis in Sardinian Patients. PloS One (2011) 6(4):e18482. doi: 10.1371/ journal.pone.0018482

64. Frau J, Cossu D, Coghe G, Lorefice L, Fenu G, Melis M, et al. Mycobacterium Avium Subsp. Paratuberculosis and Multiple Sclerosis in Sardinian Patients: Epidemiology and Clinical Features. Mult Scler (2013) 19(11):1437-42. doi: $10.1177 / 1352458513477926$

65. Mameli G, Cocco E, Frau J, Marrosu MG, Sechi LA. Epstein Barr Virus and Mycobacterium Avium Subsp. Paratuberculosis Peptides are Recognized in Sera and Cerebrospinal Fluid of MS Patients. Sci Rep (2016) 6:22401. doi: $10.1038 /$ srep 22401

66. Oldstone MB. Molecular Mimicry and Autoimmune Disease. Cell (1987) 50 (6):819-20. doi: 10.1016/0092-8674(87)90507-1

67. Salvetti M, Buttinelli C, Ristori G, Carbonari M, Cherchi M, Fiorelli M, et al. T-Lymphocyte Reactivity to the Recombinant Mycobacterial 65- and 70-kDa Heat Shock Proteins in Multiple Sclerosis. J Autoimmun (1992) 5(6):691-702. doi: 10.1016/0896-8411(92)90186-T

68. Salvetti M, Ristori G, Buttinelli C, Fiori P, Falcone M, Britton W, et al. The Immune Response to Mycobacterial 70-kDa Heat Shock Proteins Frequently Involves Autoreactive T Cells and Is Quantitatively Disregulated in Multiple Sclerosis. J Neuroimmunol (1996) 65(2):143-53. doi: 10.1016/01655728(96)00013-6

69. Cossu D, Masala S, Frau J, Cocco E, Marrosu MG, Sechi LA. Anti Mycobacterium Avium Subsp. Paratuberculosis Heat Shock Protein 70 Antibodies in the Sera of Sardinian Patients With Multiple Sclerosis. J Neurol Sci (2013) 335(1-2):131-3. doi: 10.1016/j.jns.2013.09.011

70. Cossu D, Mameli G, Masala S, Cocco E, Frau J, Marrosu MG, et al. Evaluation of the Humoral Response Against Mycobacterial Peptides, Homologous to MOG35-55, in Multiple Sclerosis Patients. J Neurol Sci (2014) 347(1-2):78-81. doi: 10.1016/j.jns.2014.09.023 
71. Mameli G, Cossu D, Cocco E, Masala S, Frau J, Marrosu MG, et al. EpsteinBarr Virus and Mycobacterium Avium Subsp. Paratuberculosis Peptides Are Cross Recognized by Anti-Myelin Basic Protein Antibodies in Multiple Sclerosis Patients. J Neuroimmunol (2014) 270(1-2):51-5. doi: 10.1016/ j.jneuroim.2014.02.013

72. Mameli G, Madeddu G, Cossu D, Galleri G, Manetti R, Babudieri S, et al. Immune Response Induced by Epstein-Barr Virus and Mycobacterium Avium Subsp. Paratuberculosis Peptides in Current and Past Infectious Mononucleosis: A Risk for Multiple Sclerosis? Eur J Neurol (2016) 23 (1):140-7. doi: 10.1111/ene.12821

73. Cossu D, Mameli G, Galleri G, Cocco E, Masala S, Frau J, et al. Human Interferon Regulatory Factor 5 Homologous Epitopes of Epstein-Barr Virus and Mycobacterium Avium Subsp. Paratuberculosis Induce a Specific Humoral and Cellular Immune Response in Multiple Sclerosis Patients. Mult Scler (2015) 21(8):984-95. doi: 10.1177/1352458514557304

74. Bellamy R. Susceptibility to Mycobacterial Infections: The Importance of Host Genetics. Genes Immun (2003) 4(1):4-11. doi: 10.1038/sj.gene.6363915

75. Frau J, Cossu D, Coghe G, Lorefice L, Fenu G, Porcu G, et al. Role of Interferon-Beta in Mycobacterium Avium Subspecies Paratuberculosis Antibody Response in Sardinian MS Patients. J Neurol Sci (2015) 349(12):249-50. doi: 10.1016/j.jns.2015.01.004

76. Cossu D, Yokoyama K, Tomizawa Y, Momotani E, Hattori N. Altered Humoral Immunity to Mycobacterial Antigens in Japanese Patients Affected by Inflammatory Demyelinating Diseases of the Central Nervous System. Sci Rep (2017) 7(1):3179. doi: 10.1038/s41598-017-03370-z

77. Cossu D, Yokoyama K, Sechi LA, Otsubo S, Tomizawa Y, Momotani E, et al. Humoral Response Against Host-Mimetic Homologous Epitopes of Mycobacterium Avium Subsp. Paratuberculosis in Japanese Multiple Sclerosis Patients. Sci Rep (2016) 6:29227. doi: 10.1038/srep29227

78. Kumar A, Sechi LA, Caboni P, Marrosu MG, Atzori L, Pieroni E. Dynamical Insights Into the Differential Characteristics of Mycobacterium Avium Subsp. Paratuberculosis Peptide Binding to HLA-DRB1 Proteins Associated With Multiple Sclerosis. N J Chem (2015) 39(2):1355-66. doi: 10.1039/C4NJ01903B

79. Frau J, Cossu D, Sardu C, Mameli G, Coghe G, Lorefice L, et al. Combining HLA-DRB1-DQB1 and Mycobacterium Avium Subspecies Paratubercolosis (MAP) Antibodies in Sardinian Multiple Sclerosis Patients: Associated or Independent Risk Factors? BMC Neurol (2016) 16(1):148. doi: 10.1186/ s12883-016-0669-1
80. Cossu D, Masala S, Cocco E, Paccagnini D, Tranquilli S, Frau J, et al. Association of Mycobacterium Avium Subsp. Paratuberculosis and SLC11A1 Polymorphisms in Sardinian Multiple Sclerosis Patients. J Infect Dev Ctries (2013) 7(3):203-7. doi: 10.3855/jidc.2737

81. Yokoyama K, Cossu D, Hoshino Y, Tomizawa Y, Momotani E, Hattori N. Anti-Mycobacterial Antibodies in Paired Cerebrospinal Fluid and Serum Samples From Japanese Patients With Multiple Sclerosis or Neuromyelitis Optica Spectrum Disorder. J Clin Med (2018) 7(12):522. doi: 10.3390/ jcm7120522

82. Slavin YN, Bo M, Caggiu E, Sechi G, Arru G, Bach H, et al. High Levels of Antibodies Against PtpA and PknG Secreted by Mycobacterium Avium Ssp. Paratuberculosis Are Present in Neuromyelitis Optica Spectrum Disorder and Multiple Sclerosis Patients. J Neuroimmunol (2018) 323:49-52. doi: 10.1016/ j.jneuroim.2018.07.007

83. Steri M, Orrù V, Idda ML, Pitzalis M, Pala M, Zara I, et al. Overexpression of the Cytokine BAFF and Autoimmunity Risk. N Engl J Med (2017) 376 (17):1615-26. doi: 10.1056/NEJMoa1610528

84. Sidore C, Orrù V, Cocco E, Steri M, Inshaw JR, Pitzalis M, et al. PRF1 Mutation Alters Immune System Activation, Inflammation, and Risk of Autoimmunity. Mult Scler (2020) 27(9):1332-40. doi: 10.1177/135245 8520963937

Conflict of Interest: The authors declare that the research was conducted in the absence of any commercial or financial relationships that could be construed as a potential conflict of interest.

Publisher's Note: All claims expressed in this article are solely those of the authors and do not necessarily represent those of their affiliated organizations, or those of the publisher, the editors and the reviewers. Any product that may be evaluated in this article, or claim that may be made by its manufacturer, is not guaranteed or endorsed by the publisher.

Copyright (c) 2021 Frau, Coghe, Lorefice, Fenu and Cocco. This is an open-access article distributed under the terms of the Creative Commons Attribution License (CC BY). The use, distribution or reproduction in other forums is permitted, provided the original author(s) and the copyright owner(s) are credited and that the original publication in this journal is cited, in accordance with accepted academic practice. No use, distribution or reproduction is permitted which does not comply with these terms. 